MATEC Web of Conferences 3, 01060 (2013)

DOI: $10.1051 /$ matecconf/20130301060

(C) Owned by the authors, published by EDP Sciences, 2013

\title{
Thermodynamics conditions for Guerbet ethanol reaction
}

\author{
R. Olcese ${ }^{1}$, and M.M. Bettahar ${ }^{2}$ \\ ${ }^{1}$ Laboratoire Réactions et Génie des Procédés (LRGP), Université de Lorraine, Nancy 54000, France \\ ${ }^{2}$ Laboratoire Structure et Réactivité des Systèmes Moléculaires Complexes (SRSMC), Faculté des Sciences et \\ Techniques, Université de Lorraine, 54506 Vandoeuvre-les-Nancy, France
}

\section{Introduction}

Ethanol $(\mathrm{EtOH})$ is now produced from fermentation of carbohydrates [1]. Guerbet reaction is a possible way to couple $\mathrm{C}-\mathrm{C}$ bonds of aliphatic alcohols towards higher carbon skeleton molecules that are suitable for diesel, gasoline, aviation fuel and chemicals [2-4]. When vaporized $\mathrm{EtOH}$ is contacted to solids at temperatures near $673.15 \mathrm{~K}$, a lot of different products are obtained containing olefins, paraffins, longer alcohols, diolefins, ketones, aldehydes, ethers, etc. Some $\mathrm{H}_{2}$ is produced and carbonaceous deposits are formed $[5,6]$.

On acidic catalyst, gas phase conversion of EtOH to aromatics hydrocarbons can be performed (zeolites) at $673-723 \mathrm{~K}$. This reaction involves the dehydration of $\mathrm{EtOH}$ to ethylene, and then ethylene is converted to unsaturated hydrocarbons and hydrogen [7]. The drawbacks of this strategy is that the mixture should be vaporized (heat-consuming) and that some hydrogen atoms abandon the carbon skeleton (loosing energy yield in drop-in fuels), however it could be used to obtain biobased aromatics hydrocarbons from $\mathrm{EtOH}$ platform.

Very acid catalyst accelerates excessive dehydration, producing short hydrocarbons without $\mathrm{OH}$ functionality capable of undergo C-C coupling. For that reason basic or multifunctional catalysts are employed for $\mathrm{EtOH}$ conversion to higher hydrocarbons $[6,8,9]$. The most accepted mechanism for Guerbet reaction using basic catalyst is the aldol mechanism (Scheme 1) [3, 9]. In the first step (Scheme 1, R1), EtOH is dehydrogenated by a solid catalyst to produce acetaldehyde (AcCO). Then AcCO can undertake acid-base catalyzed aldol addition (Scheme 1, R2). $\mathrm{H}_{2} \mathrm{O}$ is then released from the molecule. Basic catalysts have the capacity to store hydrogen by heterolytic dissociation. In a desired Guerbet reaction, adsorbed hydrogen is re-inserted into carbon skeleton (1butenal to 1-butanol in Scheme 1, R4) to generate a higher alcohol that can re-start the catalytic cycle.

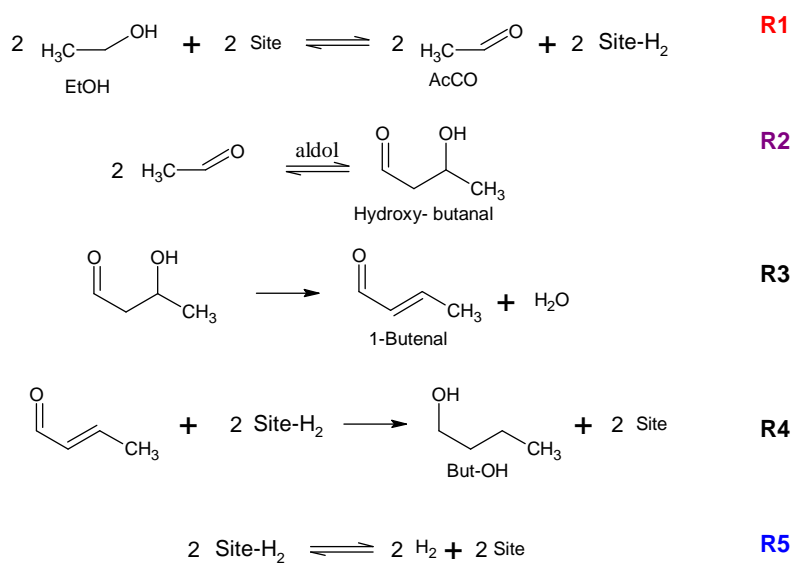

Scheme 1. Guerbet reaction of Ethanol (global reaction and most accepted catalytic mechanism).

In this work, the EtOH to butanol (But-OH) probe reaction was studied. Most of catalytic data available on C-C coupling of EtOH are on the gas phase at 1 bar, for that reason this condition was studied. However, in fermentation process, EtOH is produced in a solution of water (at $\sim 6$ wt.\% EtOH) [1], this aqueous solution was also studied. It is expected that higher alcohols (like octanol) separate spontaneously from water by decantation, avoiding energy-intensive distillation (consider that fuel EtOH should be anhydrous).

The formation of $\mathrm{AcCO}$ is not favored at low temperatures. For that reason, this study concentrates in this step of reaction (Scheme 1, R1). The determination of EtOH/AcCO equilibrium will guide experimental catalyst researchers to favorable conditions and materials. $\mathrm{R} 2$ has low $\Delta_{\mathrm{R} 2} \mathrm{G}$ in the whole range of temperature $\left(\mathrm{K}_{\mathrm{eq}}\right.$ $\mathrm{R}_{2}$ is between 2-0.02). This step can limit reaction rate but it is never impeded $(\mathrm{K}<0.01)$ in the whole range of temperature. R3 and R4 are quite favorable reactions $\left(\Delta_{\mathrm{r}} \mathrm{G}<<0\right)$. The global $\mathrm{EtOH}$ to $\mathrm{BuOH}$ reaction is quite favorable both in gas phase $(298.15-773.15 \mathrm{~K})$ and liquid phase (298.15 - 523.15 K, 1-50 bar). The equilibrium of adsorption of $\mathrm{H}_{2}$ (Scheme 1, R5) is of great importance. If $\mathrm{R} 5$ is too favored $\left(\Delta_{\mathrm{R} 5} \mathrm{G}<0\right)$, this means that $\mathrm{H}$ atoms can abandon solid in the molecular form $\left(\mathrm{H}_{2}\right)$ without going to the carbon skeleton. On the other way, if this 
reaction is too disfavored, this means that it will be more difficult to transfer $\mathrm{H}$ atoms to the carbon skeleton (R4).

\section{Methods}

Gibbs energy variation of reaction in the ideal gas phase was obtained with THERGAS (Benson's method) [10]. Liquid phase equilibrium was modeled in ASPEN Plus ® using a Gibbs free energy minimization algorithm. UNIFAC-Dortmund prediction method was used for gamma between 1-8 bars. For higher pressures (50 bar) Peng-Robinson EoS coupled to Wong-Sandler mixing rule (PR-WS) was used. At 100 bar, PR-WS did not converged in ASPEN, so Predictive Soave-RedlichKwong EoS (PSRK) was used instead.

\section{Results}

\subsection{Gas Phase}

In a first approach the equilibrium of the non-catalytic AcCO formation was studied in gas phase:

$$
\mathrm{EtOH} \leftrightarrows \mathrm{H}_{2}+\mathrm{AcCO} \quad \mathrm{R} 1 \text { (non cat.) }
$$

In the catalytic mechanism, this reaction also occurs with same thermodynamics. $\mathrm{H}_{2}$ formed is re-adsorbed for completion of the reaction to 1-butanol. Also, formally, one can consider that ethanol rather decomposes into free AcCO (observed as an intermediate [5]) and a surface complex of $\mathrm{H}_{2}$ as written in $\mathrm{R} 1$. This step corresponds to the breaking of a $\mathrm{C}-\mathrm{H}$ bond by abstraction of hydride specie by the catalyst. It is probably rate limiting, also determination of energy exchanged may be a good simulation of the energy barrier to overcome in the chemical processes involved in the Guerbet reaction.

Scheme 2 shows a probable mechanism for the formation of $\mathrm{AcCO}$ by dehydrogenation of $\mathrm{EtOH}$ on $\mathrm{MgO}$, a typical basic catalyst.

The thermodynamic properties of the hydride surface complex are not easy to predict. However, experimental data on $\mathrm{H}_{2}$-storage materials is available. Salam et al. [11] compiled data of the reaction R5_inverse (adsorption of $\mathrm{H}_{2}$ ) for some solids. Typical values for $\mathrm{H}_{2}$ storage materials (Cobalt or Magnesium based metal-organic framework, Na-ZMS-5 zeolites) are $\Delta_{\mathrm{R} 5} \mathrm{~h}=+9.4$ to +18 $\mathrm{KJ} / \mathrm{mol}$ and $\Delta_{\mathrm{R} 5} \mathrm{~S}=+120$ to $+136 \mathrm{~J} /(\mathrm{mol} . \mathrm{K})$, but significant differences can be obtained with materials like $\mathrm{Co}-\mathrm{Mg}-\mathrm{Al}$ nano-crystalline mixed oxides with $\Delta_{\mathrm{R} 5} \mathrm{~h}=+25 \mathrm{KJ} / \mathrm{mol}$ and $\Delta_{\mathrm{R} 5} \mathrm{~S}=+59 \mathrm{~J} / \mathrm{mol} . \mathrm{K}$; these values will be refereed as "Advanced solid").
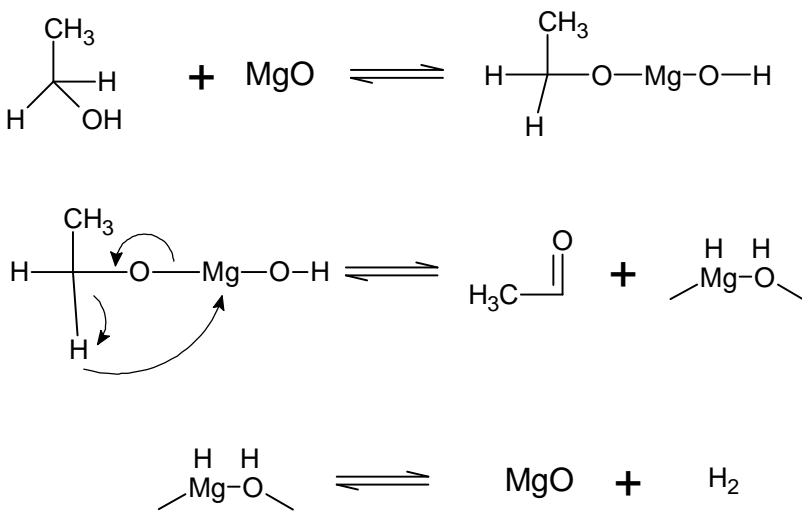

Scheme 2. A possible chemical form of R1.

The addition of "R1 -no cat-" (i.e. considering molecular $\mathrm{H}_{2}$ and not an adsorbed specie) and R5 gives R1 as showed in Scheme 1. The equilibrium constant of R1 for an ideal gas was calculated considering $\Delta_{R 5} \mathrm{~h}=+15$ $\mathrm{KJ} / \mathrm{mol}$ and $\Delta_{\mathrm{R} 5} \mathrm{~S}=+130 \mathrm{~J} /(\mathrm{mol} . \mathrm{K}$ ) for "Solid A" (a mean performing $\mathrm{H}_{2}$ storing material). R4 was always favored $(\triangle \mathrm{R} 4 \mathrm{G}<<0)$ for solids in the whole range of temperature whatever the performances of the solid catalyst.

Figure 1 shows results of calculations in ideal gas phase at 1 bar and pure EtOH, R1-no cat- is not favored at room temperature, but $\mathrm{K}_{\mathrm{eq}-\mathrm{R} 1 \text {-nocat- }}$ approach 1 at about $600 \mathrm{~K}$. The equilibrium constant of R1 in Solid A is very low in the whole temperature range. However, if we consider an advanced material, these values get enhanced significantly. Ndou et al. [5] studied EtOH conversion on $\mathrm{MgO}$ as catalyst at different temperatures, the reaction did not take place until $\mathrm{T}>673.15 \mathrm{~K}$, then a sharp increase in activity is observed and a peak in selectivity appears near $723.15 \mathrm{~K}$, then selectivity falls down at $773.15 \mathrm{~K}$, probably because of the departure of molecular $\mathrm{H}_{2}$. However, Tsuchida et al. [6,9] observed activity at temperatures as low as $545.15 \mathrm{~K}$ for advanced $\mathrm{Ca} / \mathrm{P}$ catalysts.

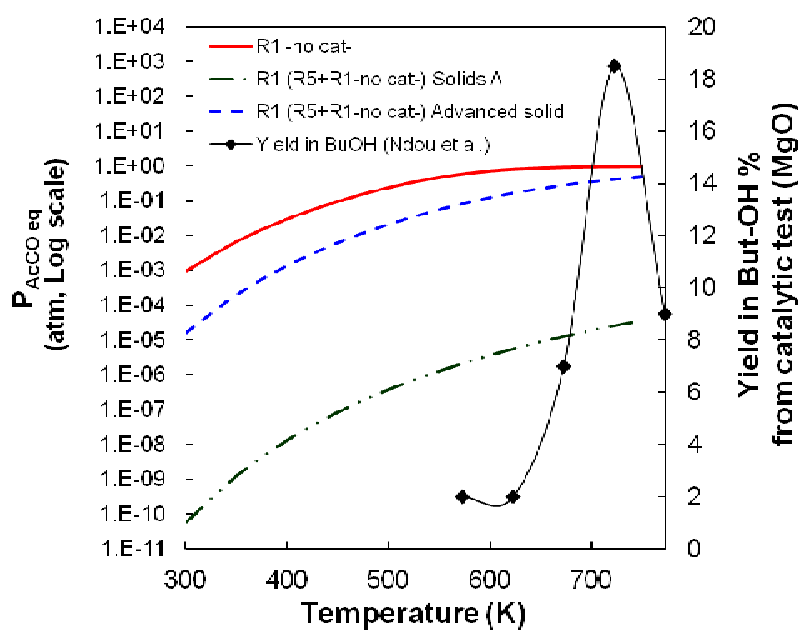

Figure 1. Plot of Keq (log scale) for different reactions as a function of temperature (1 bar, ideal gases, pure $\mathrm{EtOH}$ ) and data of catalytic conversion of EtOH into But-OH using $\mathrm{MgO}$ as catalyst.

Desorption of hydrogen (R5) should be avoided in our reaction system to prevent the departure of energy-rich 
$\mathrm{H}_{2}$ from carbon skeleton. In the "Advanced material" the $\mathrm{H}_{2}$ desorption becomes possible at $\mathrm{T}>433.15 \mathrm{~K}$ but temperatures about $523.15 \mathrm{~K}$ are needed to reach a significant value of conversion of $\mathrm{R} 1$ ( $\left.\mathrm{P}_{\mathrm{AcCOeq}}=0.01 \mathrm{bar}\right)$. So, even with the advanced material, we cannot simultaneously favor AcCO formation (R1) and impede $\mathrm{H}_{2}$ departure (R5).

\subsection{Liquid Phase}

Evaporation of water and EtOH requires energy. Liquid phase is preferred to avoid this step [8]. In order to avoid vaporization in equilibrium calculations, conditions were always $\mathrm{P}>$ Pbubble point of the mixture. In the range of 298.15 to $433.15 \mathrm{~K}$, a pressure of 8 bar satisfy the $\mathrm{P}>\mathrm{P}_{\text {bubble }}$ point conditions. In this range UNIFACDortmund method was used to model equilibrium into a RGIBBS Aspen tool (Gibbs energy minimization). A solution of 6 wt.\% EtOH, 94 wt.\% $\mathrm{H}_{2} \mathrm{O}$ was inserted into the reactor where R1-nocat- was the only possible reaction (Figure 2). A reasonable accordance is observed with UNIFAC-DMD model and PRWS model from 298.15 to $\sim 350 \mathrm{~K}$. At temperatures about $408.15 \mathrm{~K}$ and 8 bars, $\mathrm{H}_{2}$ forms a gaseous phase and equilibrium is displaced towards products. In both cases, a positive effect of temperature is observed.

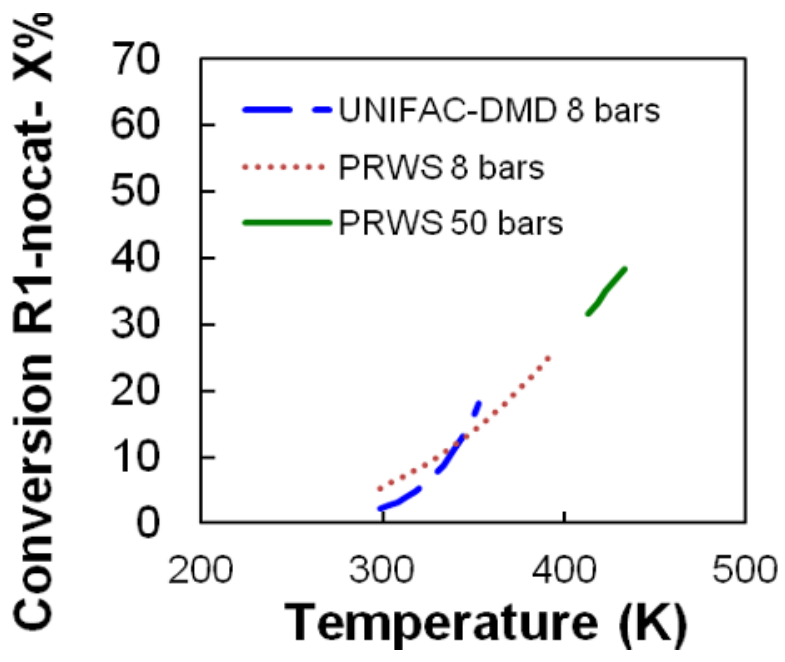

Figure 2. Equilibrium conversion of R1-no cat- at 8 bars as a function of temperature and prediction models.

At 50-100 bars only a EoS can be considered, at 50 bars the study of equilibrium conversion can be extended to $433.15 \mathrm{~K}$ (then $\mathrm{a}_{2}$ rich gas phase is formed).

In order to model equilibrium between liquid phase $\mathrm{EtOH}, \mathrm{AcCO}$ and surface complex values of $\gamma$ were calculated in a mixture of 6 wt.\% EtOH, 94 wt.\% H2O and 0.006 wt.\% AcCO (modeling the beginning of the reaction (Figure 3 ). UNIFAC-DMD (8 bars), PR-WS (50 bars) and P-SRK (100 bars) were used to calculate $\gamma_{\mathrm{i}}$ $. \mathrm{K}_{\gamma}=\gamma_{\mathrm{AcCO}} / \gamma_{\mathrm{EtOH}}$ is always about $0.7-1.3$ in the range 298.15-573.15 K, and $\mathrm{EtOH} / \mathrm{H}_{2} \mathrm{O}$ mass ratio from 6/94 to $50 / 50$. Very low effect of pressure was observed (1-100 bar).
The value of $\mathrm{C}_{\mathrm{AcCO}} / \mathrm{C}_{\mathrm{EtOH}}\left(\mathrm{K}_{\mathrm{eq}}\right.$ in ideal gas, $\mathrm{K}_{\mathrm{eq}} / \mathrm{K}_{\gamma}$ in liquids) is slightly lower for liquid phase.

If we consider that a reaction becomes possible when $\mathrm{C}_{\mathrm{AcCO}} / \mathrm{C}_{\mathrm{EtOH}}>0.01$, the advanced solid of Salam et al. [11] satisfy this condition at $493.15 \mathrm{~K}$ in the liquid phase (at this temperature liquid mixture bubble point is 25 bars). Since R4 is a very favored reaction, R2 Gibbs energy could be as low as $-120 \mathrm{KJ} / \mathrm{mol}$ (i.e. $\mathrm{H}_{2}$ can be very stable in the adsorbed form, avoiding formation of $\mathrm{H}_{2}$ ).

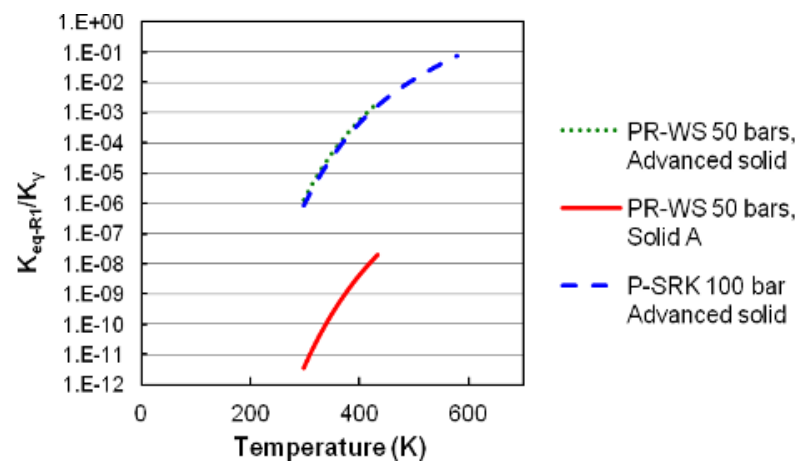

Figure 3. $\mathrm{K}_{\text {equilibirum-R1 }} / \mathrm{K}_{\gamma}\left(\gamma_{\mathrm{ACCO}} / \gamma_{\mathrm{EtOH}}\right)$ for different conditions, models, and catalytic solids.

High temperature will require great energy supply and costly high pressure equipment to avoid evaporation. Only a global cost analysis can determine the best operative conditions. Catalyst for this reaction should present desirable $\mathrm{H}_{2}$ sorption thermodynamics characteristics, but also has to respect other criterion: activity, selectivity, resistance to aqueous medium, etc. Moreover, it has to catalyze aldol condensation from AcCO. Probably, AcCO forms also a complex with catalytic sites that should be considered in more fine thermodynamic/kinetic predictions.

\section{Conclusions}

The transformation of aqueous EtOH into base hydrocarbons for drop-in fuels require advanced materials with good $\mathrm{H}_{2}$ sorption thermodynamic characteristics. $573.15 \mathrm{~K}$ and 50 bars are limit conditions to test a catalytic material; theoretically an advanced material can catalyze the EtOH Guerbet reaction at 493.15 K, 25 bars; however the concept should be still proved experimentally. Great effort of theoretic and experimental research is required to conceive a catalytic process capable to compete with other alternatives like current direct use of $\mathrm{EtOH}$ as fuel.

\section{References}

1. Ó.J. Sánchez, C.A. Cardona, Bioresour. Technol. 104 305 (2012)

2. E.L. Kunkes, D.A. Simonetti, R.M. West, J.C. Serrano-Ruiz, C.A. Gärtner, J.A. Dumesic, Science 322417 (2008)

3. J.I. Di Cosimo, G. Torres, C.R. Apesteguía, J. Catal. 208114 (2002) 
4. E. Hemo, R. Virduk, M.V. Landau, M. Herskowitz, Chemical Engineering Transactions 21 (2010)

5. A. Ndou, Appl. Catal. A 251337 (2003)

6. T. Tsuchida, T. Yoshioka, S. Sakuma, T. Takeguchi, W. Ueda, Ind. Eng. Chem. Res. 471443 (2008)

7. M. Inaba, K. Murata, M. Saito, I. Takahara, Reaction Kinetics and Catalysis Letters 88135 (2006)

8. T. Riittonen, J. Mikkola, in: 1st International Congres of Catalysis for Biorefineries, Malaga, Spain, 2011, p. 813-818

9. T. Tsuchida, J. Kubo, T. Yoshioka, S. Sakuma, T. Takeguchi, W. Ueda, J. Catal. 259183 (2008)

10. C. Muller, V. Michel, G. Scacchi, G.M. Côme, J. Chim. Phys. 921154 (1995)

11. M. Salam, S. Sufian, T. Murugesan, Nanomaterials 1 (2013) 